\title{
Carbon Footprint Study of Tesla Model 3
}

\author{
Gensheng Gui \\ GAC MOTOR CO., LTD. Guangzhou City, Guangdong, China
}

\begin{abstract}
With the application of life cycle assessment method, according to the life cycle assessment standard, the Tesla Model 3 life cycle GHG emissions are accounted applying the CALCM and GREET in this paper obtaining the following conclusions: firstly, the GHG emissions value per unit distance of Tesla Model 3 is $376 \mathrm{gCO}_{2} \mathrm{e} / \mathrm{km}, 17 \%$ higher than the average GHG emissions of B class ICEV in China, attributing mainly to the high power consumption during driving.
\end{abstract}

\section{Overview}

Energy saving and environmental protection are the two major themes for the world automobile development. Due to the high GHG emissions of the automobile industry, the resource consumption and environmental pollution caused by it cannot be ignored. At present, China's new energy vehicle industry achieves rapid development and strong growth in production and sales. In the trend of China's power cleanliness, the GHG emissions reduction of new energy vehicles has gradually become an advantage. However, the GHG emissions of different models of new energy vehicles vary greatly in the whole life cycle. The GHG emissions of certain models of new energy vehicles are even higher than traditional gasoline vehicles of the same class. As a result, the GHG emissions of new energy vehicles in their whole life cycle need to be further calculated.

Against this background, with the application of life cycle assessment method, according to the life cycle assessment standard such as ISO $14040^{[1]}$, ISO $14044^{[2]}$ and ISO $14067^{[3]}$, GAC MOTOR CO., LTD. completed the accounting of life cycle GHG emissions of Tesla Model 3 based on real vehicle disassembly data, China Automotive Life Cycle Assessment Model (CALCM) and GREET.

\section{Method}

\subsection{Goals and scope}

Applying the LCA method, this study accounted the GHG emissions of the life cycle of Tesla Model 3, analyzed the contribution of each stage of the life cycle, so as to offer guidance for the automobile enterprises to use lowcarbon materials, reduce the amount of materials, avoid the transfer of pollution, reduce energy consumption by applying low-carbon process technology, design and produce vehicles with lower GHG emissions.

\subsubsection{Functional unit}

In this report, the functional unit is the transportation service provided by Tesla Model 3 driving $1 \mathrm{~km}$, and the life time driving distance is $150,000 \mathrm{~km}$.

\subsubsection{System boundary}

Figure 1 shows that the Tesla Model 3 life cycle system boundary consists of the following stages: raw material acquisition, the production of the power battery and the automobile product, and the usage stage. In this study, the Tesla Model 3 is composed of various system components, power storage batteries, tires, lead-acid batteries, and liquid materials. 


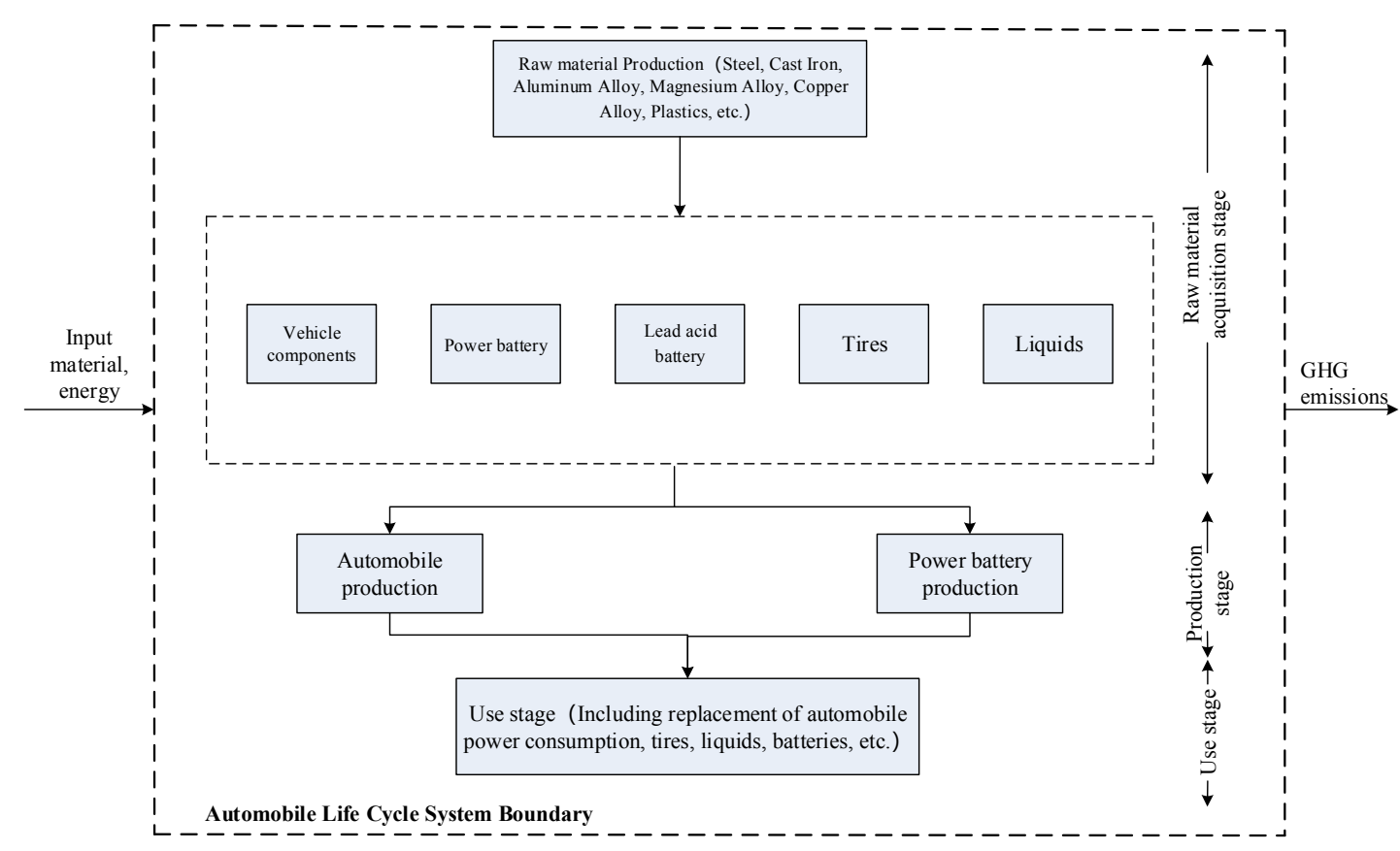

Figure 1 Tesla Model 3 vehicle life cycle system boundary

\subsection{Life cycle list data}

\subsubsection{Data source}

Each kind of raw materials (including steel, aluminum, copper and other metal materials and non-metallic materials such as plastics, glass and rubber for automobiles) in this report is represented by a typical vehicle raw material; the total mass of the vehicle's main material covered in this study is $1860.3 \mathrm{~kg}$. The Tesla Model 3 vehicle life cycle list data are derived from the disassembly. The background data for the raw material acquisition phase and power battery production comes from the GREET, and the background data for the use stage comes from CALCM, which is used to carry out the carbon emission calculation of passenger cars developed by Automotive Data Center, China Automotive Technology and Research Center Co., Ltd.

\subsubsection{Raw material acquisition stage}

This stage starts with the resources extraction from nature and ends with the application of raw materials in production facilities. The background data of steel, cast iron, aluminum alloy, magnesium alloy, plastic and other materials are derived from the GREET model; according to the disassembly of Tesla Model 3, the main system of automobiles and the list of materials for batteries, liquids, tires, etc. refer to Table 2 .

Table 2 Component material input inventory

\begin{tabular}{|c|c|c|}
\hline Material & Unit & Amount \\
\hline Steel & $\mathrm{kg}$ & 947.2 \\
\hline Cast iron & $\mathrm{kg}$ & 3.5 \\
\hline
\end{tabular}

\begin{tabular}{|c|c|c|}
\hline Wrought aluminum & $\mathrm{kg}$ & 17.4 \\
\hline Cast aluminum & $\mathrm{kg}$ & 59.1 \\
\hline Magnesium and magnesium alloys & $\mathrm{kg}$ & 6.7 \\
\hline Copper and copper alloys & $\mathrm{kg}$ & 287.1 \\
\hline Thermoplastics & $\mathrm{kg}$ & 154.5 \\
\hline Thermoplastic elastomers & $\mathrm{kg}$ & 8.4 \\
\hline Duromers & $\mathrm{kg}$ & 13.2 \\
\hline Rubber & $\mathrm{kg}$ & 8.7 \\
\hline Textiles & $\mathrm{kg}$ & 9.1 \\
\hline Lacquers & $\mathrm{kg}$ & 0.1 \\
\hline Ceramics / Glass & $\mathrm{kg}$ & 49 \\
\hline Electronics & $\mathrm{kg}$ & 23.3 \\
\hline
\end{tabular}

Table 3 Material inventory of lead acid battery

\begin{tabular}{|c|c|c|}
\hline Material & Unit & Amount \\
\hline Plastic & $\mathrm{kg}$ & 1.0 \\
\hline Lead & $\mathrm{kg}$ & 5.4 \\
\hline Sulfuric acid & $\mathrm{kg}$ & 2.5 \\
\hline Water & $\mathrm{kg}$ & 2.6 \\
\hline
\end{tabular}

Table 4 Material inventory of liquids

\begin{tabular}{|c|c|c|}
\hline Material & Unit & Amount \\
\hline Lubricants & $\mathrm{kg}$ & 2.3 \\
\hline Brake Fluid & $\mathrm{kg}$ & 1.1 \\
\hline Coolant/other glycols & $\mathrm{kg}$ & 13.1 \\
\hline Refrigerant & $\mathrm{kg}$ & 1.5 \\
\hline Washing water & $\mathrm{kg}$ & 1.3 \\
\hline
\end{tabular}

Table 5 Material inventory of tires

\begin{tabular}{|c|c|c|}
\hline Material & Unit & Amount \\
\hline Steel & $\mathrm{kg}$ & 6.2 \\
\hline Rubber & $\mathrm{kg}$ & 40.1 \\
\hline
\end{tabular}




\subsubsection{Production stage}

This stage starts with the automotive raw materials, components, and semi-finished products being applied in the production site, ends with the finished car being delivered from the production plant. For the automotive production stage, this study takes into account the energy consumption of the vehicle assembly process, which includes electrical energy, natural gas and $\mathrm{CO}_{2}$ emissions used during stamping, welding, painting, final assembly. Moreover, the energy consumption of the Tesla Model 3 power battery production process has also considered in this study. The data for the production stage of Tesla Model 3 comes from the GREET model.

\subsubsection{Use stage}

The life time driving distance is set to be $150,000 \mathrm{~km}$. The vehicle usage stage mainly includes energy consumption and material consumption. The electricity consumption of Tesla Model 3 is $26 \mathrm{kWh} / 100 \mathrm{~km}$. This study takes into account the difference between the actual driving process and the laboratory data and the electric energy loss during the charging process. The actual electricity consumption during the driving process is $35 \%$ higher than the laboratory data, referring to the survey of industry experts, while the actual electric energy loss during the charging process is set to be $12 \%$, provided by the China Electric Vehicle Charging Infrastructure Promotion Alliance. Furthermore, the replacement times of tires, batteries, liquids, etc. during the usage is set out in Table 6, and the data are derived from the survey of industry experts.

Table 6 Parameters of use stage

\begin{tabular}{|c|c|}
\hline Items & Number of replacement \\
\hline Tires & Once every $50,000 \mathrm{~km}$ \\
\hline
\end{tabular}

\begin{tabular}{|c|c|}
\hline Lead-acid battery & 2 times during life cycle \\
\hline Power battery & 0 \\
\hline Lubricant & Once every $5,000 \mathrm{~km}$ \\
\hline Brake fluid & Once every $50,000 \mathrm{~km}$ \\
\hline Coolant & Once every $50,000 \mathrm{~km}$ \\
\hline Refrigerant & Once during the life cycle \\
\hline Detergent & Once every $10,000 \mathrm{~km}$ \\
\hline
\end{tabular}

\subsection{Impact assessment}

This study applies GREET model to account Tesla Model 3 GHG emissions of the raw material acquisition stage and power battery production, and CALCM to calculate Tesla Model 3 GHG emissions of the usage stage.

\section{Results}

Using the research methods, based on the inventory analysis and impact assessment described in Chapter 2, the GHG emissions of Tesla Model 3 was obtained. The GHG emission of each stage of the life cycle are shown in Table 7.

Table 7 The life cycle GHG emissions of Tesla Model 3

\begin{tabular}{|c|c|c|}
\hline Life cycle stage & GHG emissions & Unit \\
\hline $\begin{array}{c}\text { Raw material } \\
\text { acquisition stage }\end{array}$ & 62 & $\mathrm{gCO}_{2} \mathrm{e} / \mathrm{km}$ \\
\hline Production stage & 10 & $\mathrm{gCO}_{2} \mathrm{e} / \mathrm{km}$ \\
\hline Use stage & 304 & $\mathrm{gCO}_{2} \mathrm{e} / \mathrm{km}$ \\
\hline Total & 376 & $\mathrm{gCO}_{2} \mathrm{e} / \mathrm{km}$ \\
\hline
\end{tabular}

And figure 2 shows the proportion of GHG emissions in each stage of the life cycle. The GHG emissions per unit distance of Tesla Model 3 is mainly attributed to automobile usage stage, accounting for $81 \%$, the raw material acquisition stage accounts for $16 \%$.

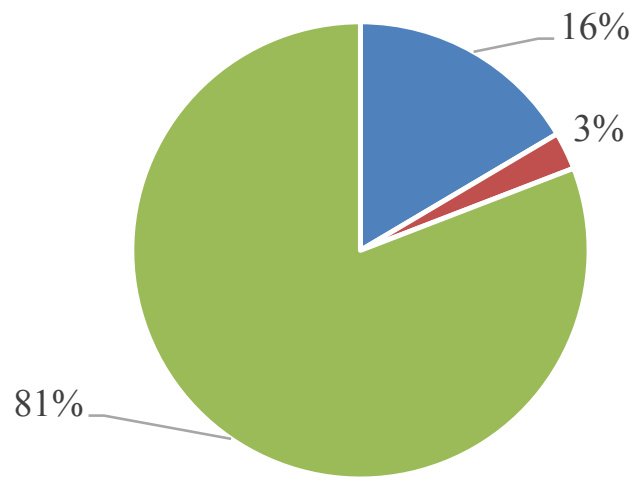

\section{- Raw material acquisition stage - Production stage $\quad$ Use stage}

Figure 2 The proportion of GHG emissions in each stage of the life cycle

Divided based on the length and wheelbase, Tesla Model 3 is B class vehicle. Tesla Model 3 life cycle GHG emissions value is $376 \mathrm{gCO}_{2} \mathrm{e} / \mathrm{km}$, while the average GHG emissions of B class ICEV is $322 \mathrm{gCO}_{2} \mathrm{e} / \mathrm{km}$. A comparison of the GHG emissions values at each stage of the life cycle with the average GHG emissions of B class ICEV is shown in figure 3. 


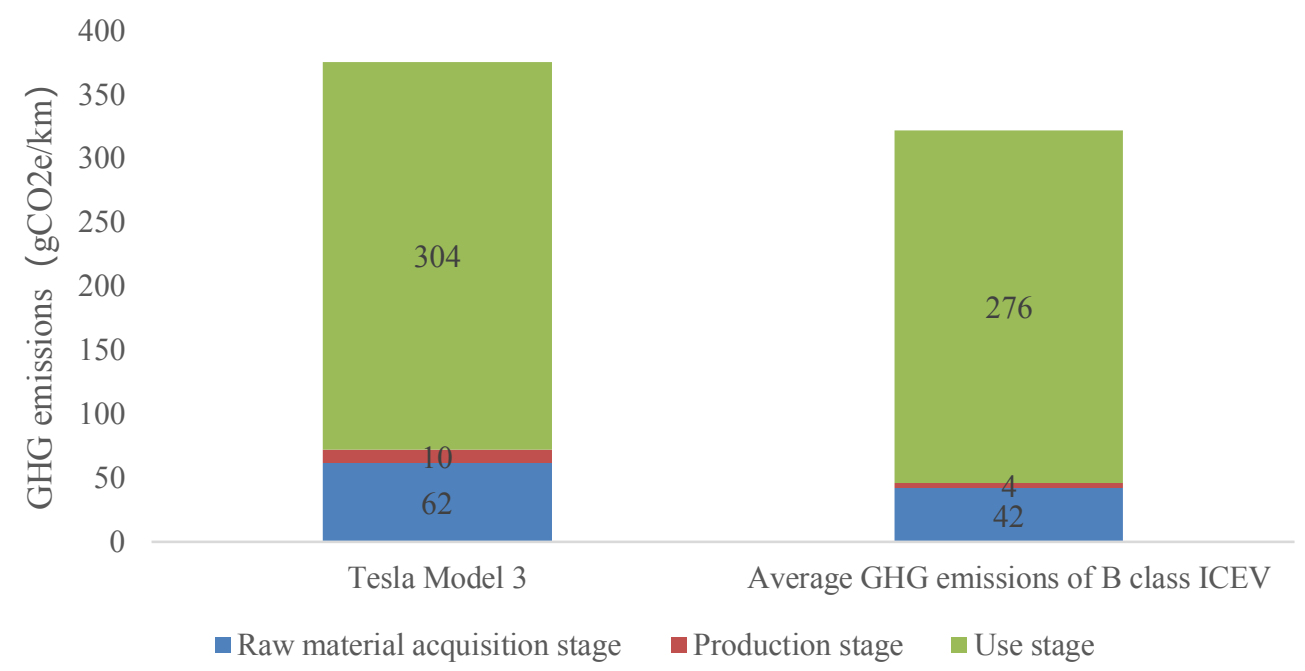

Figure 3 Comparison of GHG emissions values the Tesla Model 3 and the average GHG emissions of B class ICEV

Unlike most pure electric passenger cars, Tesla Model 3 not only has a GHG emissions higher than the average GHG emissions of same class ICEV in the raw material acquisition stage and production stage, but also has a GHG emissions value higher than the average GHG emissions of same class ICEV in the usage stage. This may be due to Tesla Model 3's power consumption is much higher than the average level of electric vehicles of the same class, resulting in a significant increase in GHG emissions during the use stage.

\section{Reference}

1. ISO, ISO 14040: 2006 Environmental ManagementLife cycle assessment-Principles and framework. 2006: International Organization for Standardization.

2. ISO, ISO 14044: 2006 Environmental management Life cycle assessment - Requirements and guidelines. 2006: International Organization for Standardization.

3. ISO, ISO 14067:2013 Greenhouse gases - Carbon footprint of products - Requirements and guidelines for quantification and communication. 2013: International Organization for Standardization. 